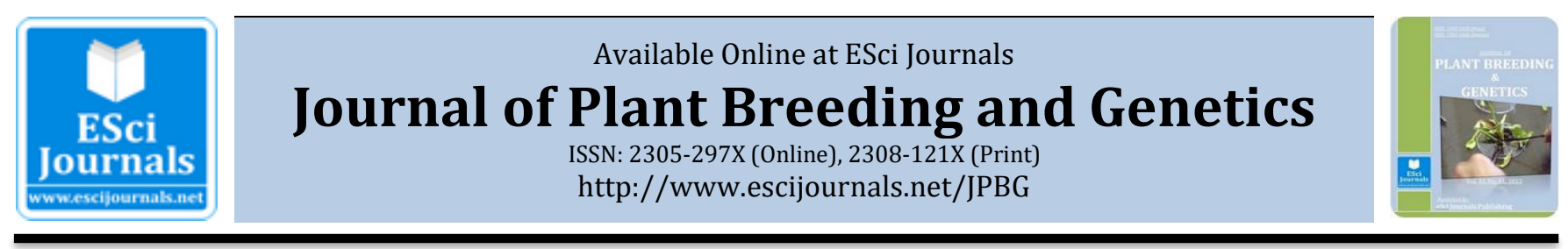

\title{
GENOTYPE X ENVIRONMENT INTERACTION AND STABILITY OF OIL CONTENT OF SESAME (SESAMUM INDICUM L.) GENOTYPES IN NORTHERN ETHIOPIA
}

\author{
Fiseha Baraki*, Gebrelibanos Gebremariam \\ ${ }^{a}$ Crop Research Core Process, Humera Agricultural Research Center, Ethiopia. \\ ${ }^{b}$ Department of Plant Sciences, Adigrat University, Ethiopia.
}

\begin{abstract}
A B S T R A C T
The experiment for oil content analysis was conducted for two growing seasons under rainfed condition (2012-2013) in Humera and Dansha, and in a single year (2013 cropping season) in Sheraro (comprising a total of five environments). The experiment comprised of 13 sesame genotypes, laid out in a randomized complete block design of three replications with the objective of determining the magnitude of Genotype x Environment Interaction (GEI)and oil content. here was highly significant $(\mathrm{p}<0.01)$ oil content variation based on genotypes, environments and GEI resulting $26 \%, 42.7 \%$ and $30.9 \%$ of the total sum of squares for the oil content variation respectively. The mean of the oil content was 53.9\%, with genotypes G4 and G11 with the highest oil content (55.1\%) each, and G8 with the lowest oil content (51.4\%). G4 was the exceptional genotype with the highest oil content (55.1\%) and oil yield (512.9 $\mathrm{kg} / \mathrm{ha}$ ). Based on the Environmental Index (EI) analysis, Environments E4 and E5 were the favourable environments, while E1, E2 and E3 were unfavourable environments for sesame oil production. According to the AMMI1(Additive main effects and multiplicative interaction) bi-plot, Genotypes G4, G13 and G10 with oil the content of 55.1\%, 54.7 and 54.2 respectively, were stable genotypes. On the other hand, genotypes G2, G8, G9, G3 and G1 were unstable genotypes in most of the environments. The AMMI 2 bi-plot showed that, genotypes G2, G3 and G9, with long vector length, were specifically adaptable genotypes and genotypes G10, G12, G4 and G7 with shorter vector length were widely adaptable in most of the environments for their oil content. Oil content of sesame varies highly both across years and locations.
\end{abstract}

Keywords: Adaptable, AMMI, bi-plot, Environment, Oil content, Oil yield, Stability.

\section{INTRODUCTION}

Sesame (Sesamum indicum L.) is an ancient oilseed crop which has been grown for over 7,500 years in Asia and Africa even in very poor growing conditions (Langham et al., 2010). Sesame is currently widely grown for its flavoursome, edible seed and high quality oil. Decorticated sesame seeds have a composition of 45$63 \%$ oil, $19-31 \%$ proteins, about $14 \%$ carbohydrates and about 3\% ash (Anilakumar et al., 2010). In addition, the seeds contain about $83 \%$ - 90\% unsaturated fatty acids, and various minor nutrients such as vitamins and minerals, large amount of characteristic lignans (methylenedioxyphenyl compounds) such as sesamin, sesamol, sesamolin and tocopherols. Due to the presence

* Corresponding Author:

Email: fish051bar@gmail.com

(C) 2018 ESci Journals Publishing. All rights reserved. of these antioxidants, Sesame oil is highly stable and rarely turns rancid in hot climates (Fukuda et al., 1985). The sesame oil is rich in unsaturated fatty acids where the fatty acids composition is $14 \%$ saturated, $39 \%$ monounsaturated, and $46 \%$ polyunsaturated fatty acids (Toma et al., 1979).

The sesame seed which contains about $50-60 \%$ oil content (Caliskan et al., 2004) is an excellent source of quality oil which is straw-like in colour and odourless that is close in quality to olive oil (Tunde-Akintunde and Akintunde, 2007). Owing to the excellent quality of the edible oil it produces, sesame is often called the queen of the oilseed crops (Tunde-Akintunde and Akintunde, 2007). The components together impart resistance against oxidative deterioration and provide nutraceutical value to the crop. For that reason, sesame seeds with high amounts of nutritional components are consumed as a 
traditional health food for its specific antihypertensive effect, anticarcinogenic, anti-inflammatory and antioxidative activity (Yokota et al., 2007).

Sesame is grown mainly for its attractive domestic and international price in Ethiopia, where there are three sesame types commonly used for commercial production and these are the Humera, Gondar and Wollega types. The Humera type is appreciated worldwide for its aroma and sweet taste and is the first sesame standard in the international market. The Humera type sesame code is not ascribed to any specific variety but to different varieties grown in the Western and Northwestern Tigray of Northern Ethiopia. It is said to be good uniform white seeds, which are quite large which makes it very suitable for bakery products. The Gondar type is also suitable for the bakery market. The major competitive advantage of the Wollega type is its high oil content (Investor Presentation, 2012).

The Western Tigray of Northern Ethiopia is the main sesame producer with large commercial farms and many small scale farmers. Furthermore, sesame also grows very well in the Northwestern Tigray of Northern Ethiopia under a few commercial farming systems and by many small scale farmers as a cash crop and for local oil extraction to produce 'ashera' (the locally extracted sesame oil). In this local oil extraction, the oil that the producers extract from a given amount of sesame seeds varies from variety to variety that harvested from different places in a different period of time giving an indication for the instability of sesame genotypes for their oil content. Different studies have been also undertaken to determine the magnitude of GEI and oil content stability of sesame (Abate et al., 2015; Zenebe and Hussien, 2009) and found that sesame oil was not stable across years and location. This study is aimed to identify and supply high yielding and stable oil content sesame variety/ies and investigating the magnitude of GEI. GEI investigation is a challenge and an opportunity for plant breeders (Fiseha et al., 2016). Because it complicates cultivar recommendation due to the inconsistency of high yielding material across different environments. On the other hand, it is also an opportunity since it allows for the recommendation of specifically adapted materials to the given environment.

\section{MATERIAL AND METHODS}

Experimental Materials: The experiment for sesame oil content analysis was conducted for two growing seasons (2012-2013) in Humera and Dansha types, and in a single year (2013 cropping season) in Sheraro (a total of five environments) under rainfed condition where: E1 and E2 are 2012 and 2013 growing seasons, respectively, in Humera; E3 and E4 are 2012 and 2013 growing seasons, respectively, in Dansha; and E5 is 2013 growing season in Sheraro. Edaphic and climatic description of the studied areas, as well as the description of the genotypes, are listed in table 1 and table 2, respectively. Thirteen sesame genotypes viz. (Acc\#031 (G1), Oro (9-1) (G2), NN-00791(G3), Acc-034 (G4), Abi-Doctor (G5), Serkamo (G6), Acc051-020sel-14 (G7), Tate (G8), Acc-051-02sel-13 (G9), Adi (G10), Higher (G11), Setit-1 (G12), Humera-1(G13)) were sown in randomized complete block design (RCBD) with three replications and evaluated for their oil content. Each genotype was randomly assigned and sown in a plot area of $2.8 \mathrm{~m}$ by $5 \mathrm{~m}$ with $1 \mathrm{~m}$ between plots and $1.5 \mathrm{~m}$ between blocks keeping inter and intra row spacing of 40 $\mathrm{cm}$ and $10 \mathrm{~cm}$, respectively.

Table 1. Agro-climatic and soil characteristics of the experimental sites

\begin{tabular}{ccccccccc}
\hline Location & $\begin{array}{c}\text { Latitude } \\
\left({ }^{\circ} \mathrm{N}\right)\end{array}$ & $\begin{array}{c}\text { Longitude } \\
\left({ }^{\circ} \mathrm{E}\right)\end{array}$ & $\begin{array}{c}\text { Altitude } \\
(\mathrm{m})\end{array}$ & $\begin{array}{c}\text { Annual } \\
\mathrm{RF}(\mathrm{mm})\end{array}$ & $\begin{array}{c}\text { Min. - Max. } \\
\text { Temp. }\left({ }^{\circ} \mathrm{c}\right)\end{array}$ & $\begin{array}{c}\text { Clay } \\
(\%)\end{array}$ & $\begin{array}{c}\text { Silt } \\
(\%)\end{array}$ & $\begin{array}{c}\text { Sand } \\
(\%)\end{array}$ \\
\hline Humera & $14^{\circ} 15^{\prime}$ & $36^{\circ} 37^{\prime}$ & 609 & 576.4 & $18.8-37.6$ & 35.6 & 25.6 & 38.6 \\
Sheraro & $14^{\circ} 24^{\prime}$ & $37^{\circ} 45^{\prime}$ & 1028 & 676.7 & $18.8-34.9$ & 21 & 27.3 & 51.7 \\
Dansha & $13^{\circ} 36^{\prime}$ & $36^{\circ} 41^{\prime}$ & 696 & 888.4 & $28.7(\mathrm{mean})$ & - & - & - \\
\hline
\end{tabular}

Table 2. Description of the sesame genotypes evaluated for their oil content.

\begin{tabular}{ccccc}
\hline Genotype name & Gen code & Status & Seed colour & Source \\
\hline Acc\#031 & G1 & Advanced line & White & WARC \\
Oro (9-1) & G2 & Advanced line & White & WARC \\
NN-0079-1 & G3 & Advanced line & White & WARC \\
Acc-034 & G4 & Advanced line & White & WARC \\
\hline
\end{tabular}




\begin{tabular}{ccccc}
\hline Abi-Doctor & G5 & Advanced line & White & WARC \\
Serkamo & G6 & Released & Brown & WARC \\
Acc-051-020sel-14 & G7 & Advanced line & Brown & WARC \\
Tate & G8 & Released & Brown & WARC \\
Acc-051-02sel-13 & G9 & Advanced line & White & WARC \\
Adi & G10 & Released & White & WARC \\
Hirhir & G11 & Farmers seed (local check) & White & HuARC \\
Setit-1 & G12 & Released (standard check) & White & HuARC \\
Humera-1 & G13 & Released (standard check) & White & HuARC \\
\hline
\end{tabular}

WARC-Werer Agricultural Research Center, HuARC-Humera Agricultural Research Center

Data Collection: Each plot had a total of seven rows, from which five experimental rows were harvested, tied in sheaves and were made to stand separately until the capsules opened. After the sheaves have dried out fully and all of the capsules opened, they were tipped out onto sturdy canvases and threshing was accomplished by knocking the sheaves. The seeds from each plot were weighed for grain yield and oil yield determination as follows.

(i) Grain yield (kg/ha): the total grain yield harvested from the net plot area was weighed using a sensitive balance.

(ii) Oil content (OC) (\%): Oil content was determined by wide line nuclear magnetic resonance (NMR).

$$
\text { Oil yield }(O Y)\left(\frac{k g}{h a}\right)=\text { grain yield }\left(\frac{k g}{h a}\right) * \text { Oil content }(\%)
$$

Statistical Analysis: Statistical estimations and computations were performed using Genstat software for mean comparisons, Excel spreadsheet for computation of ASV, Environmental Index (EI) and SIPC, and Minitab 16th ed. for Homogeneity and normality test. Homogeneity of residual variances was tested prior to a combined analysis over locations in each year as well as over locations and years using Bartlet's test (Calinski et al., 1981). Accordingly, the data collected were homogenous and all data showed normal
Composite seeds were collected from each plot and each replication bulked separately and oven dried at $130{ }^{\circ} \mathrm{C}$ for $2 \mathrm{hrs}$ and cooled for $1 \mathrm{hr}$. From each plot a sample of $22 \mathrm{~g}$ of oven dried clean seed was used for analysis of oil content by NMR (Newport analyzer) (Newport Pagnell, Bucks, UK). The NMR reads the oil content of the sample seed with reference to a standard of extracted sesame oil. The instrument provided three readings at an interval of 8 seconds and the average of the three readings was recorded for each sample and used for the oil content analysis.

(iii) Oil yield (OY) $(\mathrm{kg} / \mathrm{ha})$ : Oil yield was determined by multiplying the oil content (\%) and the grain yield in $\mathrm{kg} / \mathrm{ha}$ as the formula below.

$$
\mathrm{ASV}=\sqrt{\left[\frac{\mathrm{SS}_{\mathrm{IPCA1}}}{\mathrm{SS}_{\mathrm{IPCA} 2}}\left(\mathrm{IPCA} 1_{\text {score }}\right)\right]^{2}+\left(\mathrm{IPCA} 2_{\text {score }}\right)^{2}}
$$

Where: SS is the sum of squares; IPCA1 is the interaction of principal component axis one; and IPCA2 is the interaction of principal component axis two.

SIPC (Sum of interaction principal component) was also calculated in the excel spreadsheet using the formula developed by Sneller Sneller et al. (1997):

$$
\operatorname{SIPC}=\sum_{n=0}^{\mathrm{N}}\left|\lambda^{05}{ }_{n} \gamma_{\text {in }}\right|
$$

Where: $\lambda^{05}{ }_{n} \gamma_{i n}$ is the interaction principal component (IPC) scores for the $i^{\text {th }}$ genotype; $n$ is number of IPC; and
$\mathrm{N}$ is numthe ber of significant IPC retained in the model via F-test. 
Similarly yield stability index (YSI) was also computed in the excel spreadsheet using the formula developed by Farshadfar et al. (2011):

\section{$\mathrm{YSI}=\mathrm{RASV}+\mathrm{ROC}$}

Where: RASV- is rank of AMMI stability value and ROCis rank of oil content

Overall rank (OR) is the oil content stability rank of the sesame genotypes based on the above mentioned parameters and a genotype with a smallest value of the summation of the rank of the different stability measures considered as first ranked (the most stable) and a largest value of the summation of the rank of the different stability measures considered as last ranked (the most unstable).

\section{RESULT AND DISCUSSION}

Variance Estimation for Oil Content of Sesame Genotypes: The combined ANOVA for oil content showed that there was highly significant variation $(\mathrm{p}<0.01)$ among the genotypes, environments and Genotype $\times$ Environment Interaction. where; environment means (year, location, year $\times$ location) and Genotype $\times$ Environment Interaction, means (Genotype $\times$ Year, Genotype $x$ Location and Genotype $\times$ Year $\times$ Location) (Table 3 ). These significant variations of the genotypes, environments and the Genotype $x$ Environment Interaction, indicated that the response of the genotypes was highly variable and fluctuated in the oil content with the change in environment and these occurrences clearly confirmed the presence of Genotype x Environment Interaction.

Table 3. Combined ANOVA for the oil content (\%) of the sesame genotypes

\begin{tabular}{lccc}
\hline Source of variation & DF & SS & MS \\
\hline Rep & 2 & 0.01754 & 0.00877 \\
Treatment & 12 & 343.369 & $28.6141^{* * *}$ \\
Location & 2 & 309.059 & $154.529^{* * *}$ \\
Year & 1 & 229.951 & $229.951^{* * *}$ \\
Treatment x Location & 24 & 104.686 & $4.36193^{* * *}$ \\
Treatment x Year & 12 & 218.064 & $18.172^{* * *}$ \\
Location x Year & 1 & 24.96 & $24.96^{* * *}$ \\
Treatment x Location x Year & 12 & 86.2983 & $7.19153^{* * *}$ \\
Residual & 128 & 5.72246 & 0.04471 \\
\hline Total & 194 & 1322.13 & - \\
\hline
\end{tabular}

*** statistically significant at $\mathrm{p}<0.001$.

The AMMI model (Additive Main effects and Multiplicative Interaction) for oil content showed significant variation $(p<0.001)$ for both the main and interaction effects confirming the occurrence of a wide range of variation among the genotypes, years (seasons), locations and their interactions (Table 4). Environments had a great contribution in oil content variation and accounted about $42.7 \%$ of the total sum of squares confirming that the greatest source of variation for oil content among the genotypes were mainly the environment on which the genotypes were grown. Similar result were reported for sesame by Zenebe and Hussien (2009). Interaction effects and genotypes had $30.9 \%$ and $26 \%$ contribution for the total sum of squares correspondingly. The AMMI model extracted four significant $(\mathrm{p}<0.001)$ IPCAs from the interaction component (Table 4). These four IPCAs accounted a total
$99.8 \%$ of the interaction sum of squares. The extracted IPCAs are capable of providing an information on the interaction effect although their degree decreases from the first to the last IPCA. However, according to Zobel et al. (1988) the first two IPCAs could best explain the interaction sum of squares. Threfore, the first two IPCA's with a total of $91.1 \%$ sum of squares were used to explain the interaction effect.

The oil content average over the five environments was 53.9\% (Table 5). Among the environments, E4 (in Dansha location in 2013 cropping season) was the environment with highest oil content (56.8 \%) and E1 (in Humera location in 2012 cropping season) was the environment with the lowest oil content (51.6\%). Hence, E4 was the most favourable environment for oil production of sesame and E1 was the most unfavourable one among the growing environments for sesame oil production. 
Table 4. Combined AMMI analysis of variance for oil content (\%) of Sesame genotypes.

\begin{tabular}{lcccccc}
\hline Source of variation & $\mathrm{df}$ & TSS & TSS (\%) & GEI explained (\%) & Cumulative (\%) & MS \\
\hline Treatments & 64 & 1316.4 & 99.6 & - & - & $20.57^{* *}$ \\
Genotypes & 12 & 343.4 & 26.0 & - & - & $28.61^{* *}$ \\
Environments & 4 & 564 & 42.7 & - & - & $140.99^{* *}$ \\
Block & 10 & 0.3 & 0.0 & - & - & 0.03 \\
Interactions & 48 & 409 & 30.9 & - & - & $8.52^{* *}$ \\
IPCA 1 & 15 & 316 & - & 77.2 & 77.2 & $21.07^{* *}$ \\
IPCA 2 & 13 & 56.9 & - & 13.9 & 91.1 & $4.38^{* *}$ \\
IPCA 3 & 11 & 28.5 & - & 6.9 & 98 & $2.59^{* *}$ \\
IPCA 4 & 9 & 7.6 & - & 1.8 & 99.8 & $0.85^{* *}$ \\
Error & 120 & 5.5 & - & - & - & 0.05 \\
\hline Total & 194 & 1322.1 & - & - & - & 6.82 \\
\hline
\end{tabular}

Where: df-degrees of freedom, the TSS-total sum of squares, GEI- genotype by environment interaction and MS- mean square.

This might be due to the reason that the Dansha location is a better growing environment because it receives better annual rainfall (Table 1) with comparatively favourable temperature for sesame production. Regarding the genotypes, G4 (Acc-034) and G11 (Hirhir) were the genotypes with highest oil content (55.1\% each) and G8 (Tate) was the genotype with the lowest oil content (51.4 \%) (Table 5). Furthermore, G1 (Acc\#031) and G4 (Acc-
034) were the genotypes with the highest oil yield (514.6 $\mathrm{kg} / \mathrm{ha}$ and $512.9 \mathrm{~kg} / \mathrm{ha}$ respectively), confirming that G4 (Acc-034) was the exceptional genotype with the highest oil content and oil yield in comparison to the other ones. These oil content differences among the genotypes might be explained by the inherent genetic potential difference of the genotypes and/or due to the environments on which the genotypes were tested.

Table 5. Oil content (\%) and combined oil yield (kg/ha) recorded from 13 sesame genotypes in five environments.

\begin{tabular}{cccccccc}
\hline \multirow{2}{*}{ Genotype } & \multicolumn{5}{c}{ Environments } & $\begin{array}{c}\text { Genotype Mean } \\
\text { OC (\%) }\end{array}$ & $\begin{array}{c}\text { Genotype Mean OY } \\
\text { (kg/ha) }\end{array}$ \\
\cline { 2 - 5 } & E1 & E2 & E3 & E4 & E5 & $514.6^{\mathrm{a}}$ \\
G1 & 54.3 & 54.8 & 55.8 & 54.3 & 55.8 & $55.0^{\mathrm{ab}}$ & $340.4^{\mathrm{e}}$ \\
G3 & 48.5 & 49.9 & 50.3 & 59.1 & 51.0 & $51.7^{\mathrm{i}}$ & $4^{\mathrm{a}}$ \\
G4 & 54.0 & 53.3 & 57.1 & 53.6 & 54.6 & $54.5^{\mathrm{d}}$ & $512.9^{\mathrm{a}}$ \\
G5 & 53.1 & 55.8 & 53.9 & 57.3 & 55.1 & $55.1^{\mathrm{a}}$ & $3^{\mathrm{a}}$ \\
G6 & 52.8 & 54.3 & 55.8 & 56.7 & 54.6 & $54.9^{\mathrm{bc}}$ & $411.6^{\mathrm{bcd}}$ \\
G7 & 51.8 & 52.7 & 55.8 & 56.0 & 53.7 & $54.0^{\mathrm{f}}$ & $370.7^{\mathrm{de}}$ \\
G8 & 48.4 & 51.6 & 51.0 & 57.0 & 53.5 & $52.7^{\mathrm{g}}$ & $348^{8 \mathrm{e}}$ \\
G9 & 46.5 & 52.2 & 51.6 & 57.9 & 51.9 & $52.0^{\mathrm{h}}$ & $358.2^{\mathrm{de}}$ \\
G10 & 51.1 & 53.7 & 53.9 & 57.4 & 54.9 & $54.2^{\mathrm{e}}$ & $400.8^{\mathrm{cde}}$ \\
G11 & 54.0 & 53.8 & 56.8 & 56.7 & 54.2 & $55.1^{\mathrm{a}}$ & $464.3^{\mathrm{ab}}$ \\
G12 & 53.2 & 54.5 & 53.1 & 58.4 & 54.9 & $54.8^{\mathrm{c}}$ & $469.5^{\mathrm{ab}}$ \\
G13 & 52.8 & 54.7 & 52.8 & 57.2 & 56.0 & $54.7^{\mathrm{c}}$ & $456.4^{\mathrm{abc}}$ \\
\hline Env Mean & 51.6 & 53.2 & 53.6 & 56.8 & 54.0 & 53.9 & 420.0 \\
\hline
\end{tabular}

Where: E1, E2, E3, E4 and E5 refers to environments 1, 2, 3, 4 and 5, respectively. OC - oil content. OY- oil yield

Based on the EI (Environmental Index), E5 (2013 growing seasons in Dansha) with smallest EI value (0.098) was the most stable environment on which most of the sesame genotypes showed almost similar performance in their oil content (Table 6). In contrast to this, E4 (2012 growing seasons in Dansha) with 
highest EI value (2.998) was the most unstable environment on which some of the sesame genotypes showed the highest performance and the others showed the lowest performances for their oil content. Similarly, based on the ASV, E4 (2012 growing seasons in Dansha) with the highest ASV (14.71) was the most unstable environment (Table 6). According to Zali et al. (2012), environments are often classified as favourable and unfavourable ones based on the EI, where environments with a negative index are considered as unfavourable and those with positive, regarded as favourable. Accordingly, E4 and E5 with positive EI were the environments favourable for sesame oil production, and E1, E2 and E3 with negative EI were environments unfavourable for sesame oil production.

Table 6. Environmental Index (EI) and AMMI Stability Value (ASV) of the growing environments.

\begin{tabular}{ccccccc}
\hline Environment & Em (\%) & EI & IPCA1 & IPCA2 & ASV & Rank \\
\hline E1 & 51.6 & -2.242 & 1.17015 & 0.62533 & 6.53 & 3 \\
E2 & 53.2 & -0.622 & 0.00044 & 0.73742 & 0.74 & 1 \\
E3 & 53.6 & -0.232 & 1.36798 & -1.6034 & 7.76 & 4 \\
E4 & 56.8 & 2.998 & -2.6478 & -0.5205 & 14.71 & 5 \\
E5 & 53.9 & 0.098 & 0.10917 & 0.76114 & 0.97 & 2 \\
Grand mean OC (\%) & 53.9 & & & & & \\
\hline
\end{tabular}

Where: Em-environmental means.

Oil Content Stability Based on Stability Measures from AMMI Model

AMMI Stability Value (ASV) Analysis: The ASV is the distance from the coordinate point to the origin in a twodimensional scattergram of IPCA1 scores against IPCA2 scores in the AMMI model (Purchase, 1997). The genotypes with larger magnitude of IPCA score are the more specifically adapted to certain environments and those with smaller IPCA scores indicate a more stable genotype across environments. In view of that, G13 with lowest ASV (0.19) followed by G4 (0.59) were the most stable genotypes; whereas, G3 (8.83) followed by G2 (7.87) were ranked as less stable and more sensitive genotypes indicating their oil contents were highly fluctuating over the growing environments (Table 7). Zenebe and Hussien (2009) also reported that there were some sesame genotypes with higher ASV and claimed as genotypes with less stable.

Sum of Interaction Principal Component (SIPC): Sum of interaction principal component (SIPC) is another stability statistical analysis from AMMI model developed by (Sneller et al., 1997). It is the sum of the absolute value of IPC scores (SIPC) of the genotypes that were retained in the AMMI model via F-tests. The genotypes with smaller SIPC are considered as the most stable and widely adapted otherwise specifically adapted. With respect to SIPC G7 (1.06), it was the most stable genotype and considered as widely adapted; and G6 (3.033) and G4 (2.82) as unstable genotypes with a highly variable performance of the oil content across environments (Table 7). Zali et al. (2012), calculated the SIPC value of the chick pea genotypes and these authors claimed for the genotypes with the smallest SIPC value as stable genotypes and for the genotypes with larger SIPC values as unstable genotypes.

Yield Stability Index (YSI) Analysis: Yield stability index (YSI) is recommended as a measure of stability, which is calculated by summing the rank of mean grain yield across environments and rank of AMMI stability value of genotypes. The genotypes with the lowest value of this parameter are desirable genotypes with high mean oil content and stability. Hence, YSI identified G4 and G13 as the most stable genotypes for their oil content, respectively, whereas, G2 was recognized as the most unstable genotype as its oil content highly fluctuates over the growing environments (Table 7). Based on the OR (Overall rank) of the genotypes calculated from the different stability parameters, G13 was the most stable genotype for its oil content followed by G12. On the other hand, G2 followed by G9, with highest overall rank value, were the most unstable genotypes for their oil content.Gebru and Abay (2013) also found some wheat genotypes with the highest overall rank value and recognized as the unstable genotypes. 
Table 7. Mean oil content (OC), various stability measures from the AMMI model and their ranking order.

\begin{tabular}{cccccccccccc}
\hline Gen & OC (\%) & Rank & IPCA1 & IPCA2 & ASV & Rank & YSI & Rank & SIPC & Rank & OR \\
\hline G1 & 54.97 & 3 & 1.27471 & 0.48186 & 7.08 & 11 & 14 & 5 & 2.34908 & 11 & 7 \\
G2 & 51.74 & 12 & -1.4175 & -0.572 & 7.87 & 12 & 24 & 10 & 1.62449 & 5 & 11 \\
G3 & 54.52 & 7 & 1.58986 & -0.3985 & 8.83 & 13 & 20 & 8 & 1.92029 & 8 & 9 \\
G4 & 55.07 & 2 & 0.10292 & 0.68597 & 0.57 & 2 & 4 & 1 & 2.82099 & 12 & 3 \\
G5 & 54.85 & 4 & 0.46249 & -0.3072 & 2.57 & 5 & 9 & 3 & 1.85606 & 7 & 4 \\
G6 & 54.01 & 9 & 0.53698 & -0.7758 & 2.98 & 6 & 15 & 6 & 3.03265 & 13 & 8 \\
G7 & 52.69 & 10 & -0.5405 & 0.41849 & 3 & 7 & 17 & 7 & 1.0602 & 1 & 6 \\
G8 & 51.36 & 13 & -1.1626 & 0.0955 & 6.46 & 10 & 23 & 9 & 1.51203 & 4 & 9 \\
G9 & 52.02 & 11 & -1.1358 & -0.6396 & 6.31 & 9 & 20 & 8 & 2.24469 & 10 & 10 \\
G10 & 54.22 & 8 & -0.148 & 0.00146 & 0.82 & 3 & 11 & 4 & 1.69582 & 6 & 5 \\
G11 & 55.09 & 1 & 0.74588 & -0.6494 & 4.14 & 8 & 9 & 3 & 2.05088 & 9 & 5 \\
G12 & 54.81 & 5 & -0.2741 & 0.63022 & 1.52 & 4 & 9 & 3 & 1.12201 & 2 & 2 \\
G13 & 54.71 & 6 & -0.0343 & 1.02895 & 0.19 & 1 & 7 & 2 & 1.48738 & 3 & 1 \\
\hline
\end{tabular}

Where: YSI-yield stability index, SIPC-sum of interaction principal component, OR-over all rank.

AMMI 1 bi-plot: the graphical representation of AMMI1 bi-plot analysis reveals the main effect means on the abscissa and IPCA-1 scores of both host genotypes as well as the environments simultaneously on the ordinate. The interaction is described in terms of differential sensitivities of the genotypes to the most discriminating environmental variable that can be constructed. Displacement along the abscissa reflects differences in main effects, whereas displacement along the ordinate illustrates differences in interaction effects. Host genotypes or environments appearing almost on a perpendicular line have similar means and those falling almost on a horizontal line have similar interaction patterns. According to Yan and Tinker (2006), genotypes with IPCA-1 scores close to zero have small interactions and hence show wider adaptation to the tested environments. A large host genotype IPCA-1 score has high interactions and reflects more specific adaptation to the environments with IPCA- 1 values of the same sign (either positive or negative). Accordingly, genotypes G2, G8, G9, G3 and G1 which have relatively larger IPCA-1 scores have a larger contribution for the GEI and are unstable genotypes in most of the environments. Whereas, G4, G13 and G10 were genotypes with smaller IPCA-1 scores having a low contribution for the GEI and are stable in most of the environments (Figure 1).

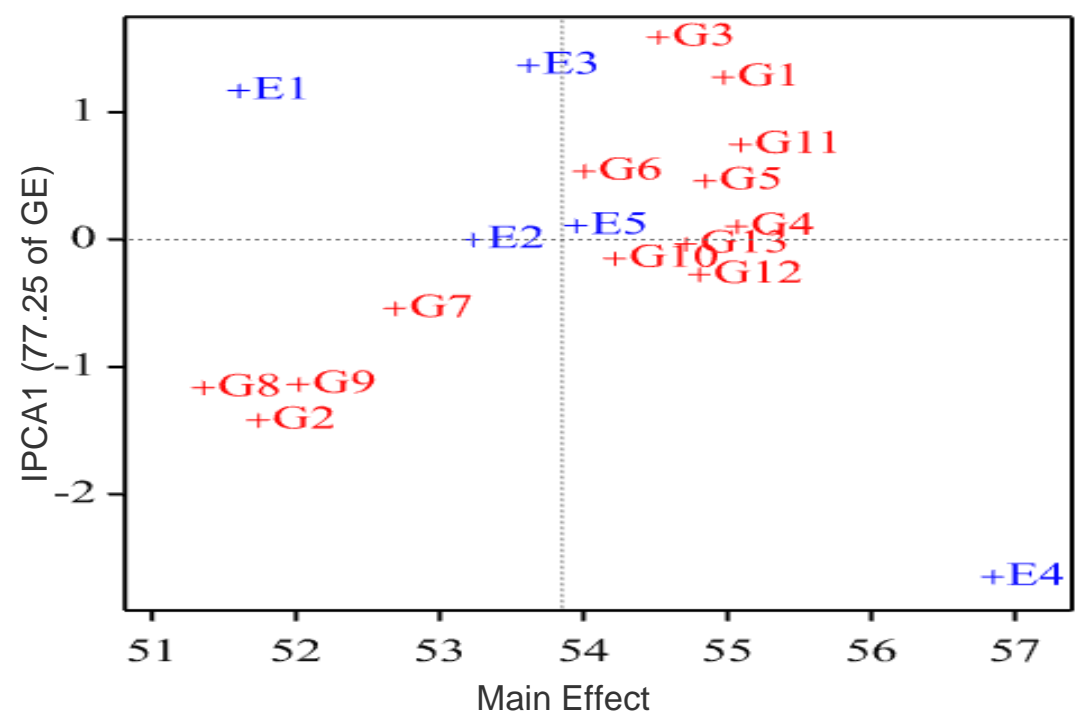

Figure 1. AMMI1 bi-plot showing Genotype and Environmental means against IPCA1 Where the environments are represented by (E) and the genotypes are represented by (G). 
Regarding the environments, E1, E3 and E4 were the environments with larger IPCA-1 scores indicating their favorability for some of the genotypes and unfavourable for the others. Whereas E2 and E5, with smaller IPCA-1 scores, were the environments averagely favourable for most of the genotypes.

AMMI 2 bi-plot: The AMMI 2 bi-plot, containing IPCA1 in the X-axis and IPCA2 in the Y-axis, is plotted in figure 2. The first interaction principal component (IPC1 or PC1) contained $77.25 \%$ and the second interaction principal component (IPC2 or PC2) explained about $13.92 \%$ and the two interaction principal components cumulatively explained about $91.17 \%$ of the sum of squares of the genotype by environment interaction of the genotypes (Figure 3). The closer the genotypes to the origin are the more stable they are, and the farthest the genotypes are from the origin the more unstable they are. In addition, the closer the genotypes are to the given vector of any environment is the more adaptive to that specific environment and the farthest the genotypes are to the given vector of any environment, the less adaptive to that specific environment they are (Purchase, 1997). Accordingly, genotypes G2, G3 and G9 are far apart from the bi-plot origin indicating these genotypes as the more responsive and contributed largely to the interaction component and considered as specifically adapted genotypes concerning their oil content. On the other hand, G10, G12, G4 and G7 were the genotypes with least contribution to the interaction component as they are located near to the bi-plot origin indicating their wider adaptability for their oil content (Figure 2). The performance of a genotype in an environment is better than average if the angle between its vector and the environment's vector is $\left\langle 90^{\circ}\right.$; it is poorer than average if the angle is $>90^{\circ}$; and it is near average if the angle is about $90^{\circ}$ (Yan and Tinker, 2006). Accordingly, the adaptability of the genotypes in the environments; genotype G1was adaptive to E1, because of the narrow angle between the vectors of G1 and E1; genotypes G6 and G2 were adaptive to E3 and E4, respectively; and genotypes G12 and G4 were adaptive to environments E2 and E5, respectively.

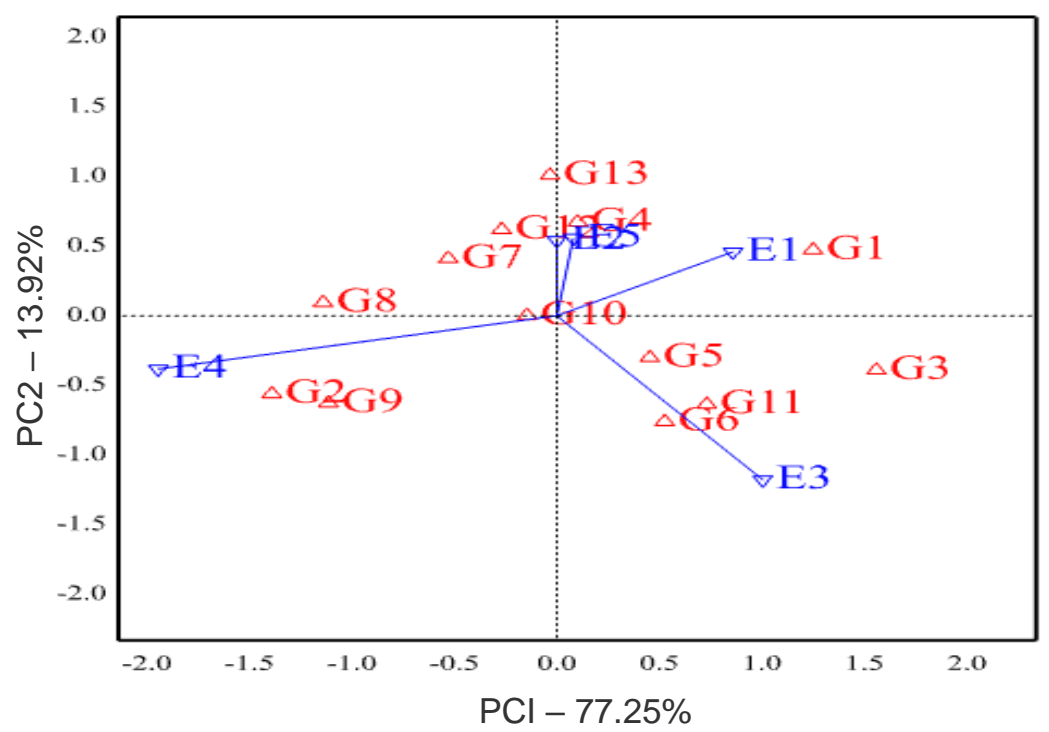

Figure 2. AMMI2 bi-plot showing PC1 versus PC2 indicating the stability of the Genotypes Where the environments are represented by $(\mathrm{E})$ and the genotypes are represented by $(\mathrm{G})$.

\section{CONCLUSIONS}

The significant variations of the genotypes, environments and their interaction indicated that the response of the genotypes was highly variable and fluctuated in the oil content and these occurrences clearly declared the existence of GEI and environments had a great contribution for oil content variation which accounted for $42.7 \%$ of the total sum of squares.

The mean of the oil content over the five environments was 53.9\%, with the highest oil content of G4 (Acc-034) and G11 (Hirhir) and with the lowest oil content of G8 (Tate). Generally, most of the genotypes were significantly different among each other regarding their oil content yield. All these differences in the oil content 
among the genotypes might be due to the inherent genetic potential differences of them and/or due to the environment on which the genotypes were tested and/or due to the interaction. Regarding to the environments, E4 and E5 were the environments favourable for sesame oil production and E1, E2 and E3 were the environments unfavourable for sesame oil production.

Genotypes G2, G8, G9, G3 and G1 presented larger contribution for the GEI and were unstable genotypes in most of the environments. Whereas, genotypes G4, G13 and G10 presented low contribution for the GEI and were stable in most of the environments. Generally, based on the investigations of this study, the performance of the sesame genotypes in terms of oil content and oil yield varies highly and was unstable both across years and locations which suggests that any researches related to sesame oil content and oil yield should be undertaken across years and locations.

\section{REFERENCES}

Abate, M., F. Mekbib, A. Ayana and M. Nigussie. 2015. Genotype x Environment and Stability Analysis of Oil Content in Sesame (Sesamum indicum L.) Evaluated Across Diverse Agro-ecologies of the Awash Valleys in Ethiopia. American Journal of Experimental Agriculture, 9: 1-12.

Anilakumar, K. R., A. Pal, F. Khanum and A. S. Bawa. 2010. Nutritional, medicinal and industrial uses of sesame (Sesamum indicum L.) seeds-an overview. Agriculturae Conspectus Scientificus, 75: 159-168.

Calinski, T., R. G. D. Steel and J. H. Torrie. 1981. Principles and Procedures of Statistics: A Biometrical Approach. Biometrics, 37: 859.

Caliskan, S., M. Arslan, H. Arioglu and N. Isler. 2004. Effect of planting method and plant population on growth and yield of sesame (Sesamum indicum L.) in a Mediterranean type of environment. Asian Journal of Plant Sciences, 3: 610-613.

Farshadfar, E., Z. Vaisi and A. Yaghotipoor. 2011. Non parametric estimation of phenotypic stability in wheat-barley disomic addition lines. Annals of Biological Research, 2: 586-598.

Fiseha, B., T. Yemane and A. Fetien. 2016. Analysis of genotype $\mathrm{x}$ environment interaction and seed yield stability of sesame in Northern Ethiopia. Journal of Plant Breeding and Crop Science, 8: 240-249.

Fukuda, Y., T. Osawa, M. Namiki and T. Ozaki. 1985. Studies on Antioxidative Substances in Sesame Seed. Agricultural and Biological Chemistry, 49: 301-306.
Gebru, H. and F. Abay. 2013. Evaluation of Bread Wheat Genotypes for their Adaptability in Wheat Growing Areas of Tigray Region, Northern Ethiopia. Journal of Biodiversity \& Endangered Species, 01.

Investor Presentation. 2012. The Business Case for Investing in the Hulling and Export of Sesame Seeds in Ethiopia. The Tel Aviv and Central Chamber of Commerce, Hasmonean Street, Aviv, Israel.

Langham, D. R., J. Riney, G. Smith, T. Wiemers, D. Pepper and T. Speed. 2010. Sesame Producers Guide. Sesaco Corp, Hobart, OK, p. 3341.

Minitab. 1998. MINITAB users guide, released 16.0. MINITAB Inc.

Purchase, J. L. 1997. Parametric analysis to describe genotype $\mathrm{x}$ environment interaction and yield stability in winter wheat (Unpublished) Ph.D. thesis, University of the Free State, Bloemfontein, South Africa.

Sneller, C. H., L. Kilgore-Norquest and D. Dombek. 1997. Repeatability of Yield Stability Statistics in Soybean. Crop Science, 37: 383.

Toma, R. B., M. M. Tabekhia and J. D. Williams. 1979. Phytate and oxalate contents in sesame seed (Sesamum indicum 1). Nutrition Reports International (USA), 20: 25-31.

Tunde-Akintunde, T. Y. and B. O. Akintunde. 2007. Effect of moisture content and variety on selected physical properties of beniseed. Agricultural Engineering International: CIGR Journal: 01-14.

Yan, W. and N. A. Tinker. 2006. Biplot analysis of multienvironment trial data: Principles and applications. Canadian Journal of Plant Science, 86: 623-645.

Yokota, T., Y. Matsuzaki, M. Koyama, T. Hitomi, M. Kawanaka, M. Enoki-Konishi, Y. Okuyama, J. Takayasu, H. Nishino, A. Nishikawa, T. Osawa and T. Sakai. 2007. Sesamin, a lignan of sesame, downregulates cyclin D1 protein expression in human tumor cells. Cancer Science, 98: 1447-1453.

Zali, H., E. Farshadfar, S. H. Sabaghpour and R. Karimizadeh. 2012. Evaluation of genotypex environment interaction in chickpea using measures of stability from AMMI model. Annals of Biological Research, 3: 3126-3136.

Zenebe, M. and M. Hussien. 2009. Study on genotype X environment interaction of oil content in sesame (Sesamum indicum L.). Middle East Journal of Scientific Research, 4: 100-104.

Zobel, R. W., M. J. Wright and H. G. Gauch. 1988. Statistical Analysis of a Yield Trial. Agronomy Journal, 80: 388. 